\title{
HealthCare.gov Shares Personal Data with Third Parties
}

According to the Associated Press, the Centers for Medicare and Medicaid's (CMS) website, HealthCare.gov, has been sending consumers' personal data to private companies that specialize in advertising and analyzing Internet data for performance and marketing (1). What information is being disclosed was not immediately clear, but it could include age, income, ZIP code, and smoking status. It could also include a computer's Internet address, which can identify a person's name or address when combined with other information collected by sophisticated online marketing or advertising firms. "We deploy tools on the window shopping application that collect basic information to optimize and assess system performance," said CMS's Aaron Albright in a statement. "We believe that the use of these tools are common and represent best practices for a typical e-commerce site." There is no evidence that personal information has been misused. But connections to dozens of third-party tech firms were documented by technology experts who analyzed HealthCare.gov and then confirmed by AP. A handful of the companies were also collecting highly specific information.

Created under the Affordable Care Act (ACA, Obamacare), HealthCare.gov is the online gateway to government-subsidized private insurance for people who lack coverage on the job. It serves consumers in $\mathbf{3 7}$ states, while the remaining states operate their own insurance markets.

Marilyn Tavenner, administrator of CMS, resigned last Friday, effective February 1. Much maligned for the shaky roll-out of HealthCare.gov, it is unclear if Tavenner's resignation and the revelation of the breech in patient confidentiality are related.

\section{References}

1. Associated press. Government health care website quietly sharing personal data. Available at: http://www.cnbc.com/id/102355634 (accessed 1/22/15).

2. Alonso-Zaldivar R. Medicare chief steps down, ran health care rollout. Available at: http://abcnews.go.com/Health/wireStory/medicare-chief-steps-part-health-care-roll$\underline{28270777}$ (accessed 1/22/15). 